\title{
Efeito da aplicação de nitrogênio e de piraclostrobina em plantas de tomateiro cultivar Micro-Tom
}

\author{
Emanuela Garbin Martinazzo ${ }^{1}$, Anelise Tessari Perboni ${ }^{2}$, Monica Tamires Tejada ${ }^{3}$, \\ Douglas Antonio Posso ${ }^{4}$, Ana Carolina Silva Galdino ${ }^{4}$, Marcos Antonio Bacarin*
}

10.1590/0034-737X201663050012

\section{RESUMO}

Fungicidas do grupo químico das estrobilurinas ganharam novas perspectivas de uso, em vista das vantagens obtidas pela ação dos efeitos fisiológicos positivos sobre as plantas. Este trabalho teve como objetivo verificar o efeito da piraclostrobina nos teores de pigmentos fotossintéticos e de nitrogênio na atividade da enzima redutase do nitrato, em plantas de tomateiro cv. Micro-Tom, cultivadas com diferentes doses de nitrogênio. Aos 21 dias após o transplante (DAT), as plantas foram submetidas aos tratamentos: solução nutritiva completa, sem piraclostrobina; solução nutritiva completa, com piraclostrobina; solução nutritiva com $1 \frac{2}{2}$ força iônica de nitrogênio, sem piraclostrobina; e solução nutritiva com $1 / 2$ força iônica de nitrogênio, com piraclostrobina. A aplicação da piraclostrobina foi repetida aos 35 DAT. Aos 28 e 42 DAT, determinaram-se o teor de pigmentos fotossintéticos, o nitrogênio total e a atividade da enzima redutase do nitrato. A aplicação de piraclostrobina promoveu aumento dos teores de pigmentos apenas aos 28 DAT, nas plantas com fornecimento reduzido de nitrogênio. Duas aplicações de piraclostrobina não influenciaram no conteúdo de nitrogênio e na atividade da redutase do nitrato de plantas de tomateiro cv. Micro-Tom, cultivadas em solução nutritiva de Hoagland e Arnon.

Palavras-chave: fungicidas; estrobilurinas; pigmentos fotossintéticos; redutase do nitrato.

\begin{abstract}
Effect of nitrogen application and pyraclostrobin in tomato plants cv. Micro-Tom

Fungicides of the strobilurin chemical group gained new perspective, because the benefits obtained by the action of positive physiological effects in plants. The study aimed to verify the effect of pyraclostrobin in the content of photosynthetic pigments, nitrogen and activity of the enzyme nitrate reductase in tomato plants cv. Micro-Tom cultured with different nitrogen rates. At 21 days after transplanting (DAT) the plants were subjected to treatments: complete nutrient solution without pyraclostrobin; complete nutrient solution with pyraclostrobin; nutrient solution $1 / 2$ ionic strength of the nitrogen without pyraclostrobin and nutrient solution $1 / 2$ ionic strength of the nitrogen with pyraclostrobin. The application of pyraclostrobin was repeated at 35 DAT. At 28 and 42 DAT was determined content of photosynthetic pigments and total nitrogen and nitrate reductase activity. The application of pyraclostrobin promoted an increase in pigment only at 28 DAT, plants with low nitrogen supply. Two applications of pyraclostrobin did not influence the nitrogen content and nitrate reductase activity in tomato plants cv. Micro-Tom grown in nutrient solution Hoagland and Arnon.
\end{abstract}

Key words: fungicides; strobilurin; photosynthetic pigments; nitrate reductase.

\footnotetext{
Submetido em 12/03/2015 e aprovado em 27/04/2016.

Universidade Federal de Pelotas, Departamento de Botânica, Pelotas, Rio Grande do Sul, Brasil. Bolsista PNPD Institucional CAPES. emartinazzo@gmail.com

${ }^{2}$ Universidade Federal de Pelotas, Departamento de Botânica, Pelotas, Rio Grande do Sul, Brasil. aneperboni@yahoo.com.br; marcos.baccarin@gmail.com

Universidade Federal de Pelotas, Pelotas, Rio Grande do Sul, Brasil. Bolsista de Iniciação Científica FAPERGS. monicatejada-@hotmail.com

${ }^{4}$ Universidade Federal de Pelotas, Pelotas, Rio Grande do Sul, Brasil. Bolsista de Iniciação Científica CNPq. douglasposso@hotmail.com; caarolgaldino@gmail.com

*Autor para correspondência: marcos.baccarin@gmail.com
} 


\section{INTRODUÇÃO}

As estrobilurinas vêm sendo utilizadas para o controle de doenças foliares em diferentes culturas, como milho, milheto, soja, trigo e feijão (Sudisha et al., 2005; Kozlowski et al., 2009; Henry et al., 2011; Santana et al., 2011; Da Costa et al., 2012). A piraclostrobina, fungicida do grupo químico das estrobilurinas, comercialmente utilizada pela primeira vez em 2002 (Bartlett et al., 2002), apresenta amplo espectro para uso em uma grande variedade de culturas (Bredemeier \& Mundstock 2000). A ação desses fungicidas ocorre por meio da inibição da cadeia respiratória mitocondrial, ao nível de complexo III, bloqueando a transferência de elétrons entre o citocromo $b$ e o citocromo $c_{1} \mathrm{e}$ a produção de adenosina trifosfato (ATP), interferindo, dessa forma, na respiração dos fungos (Duarte et al., 2009).

Alguns autores reconhecem que, além da atuação como fungicida, a piraclostrobina tem demonstrado efeito de promoção do crescimento em certas espécies vegetais, como soja, banana, uva e milho (Lima et al., 2009; Tsumanuma et al., 2010; Diaz-Espejo et al., 2012; Lima et $a l ., 2012)$. Esse efeito fisiológico positivo pode ser atribuído a uma série de fatores, como o aumento da eficiência do uso de água e de nitrogênio, a inibição da degradação da clorofila, o atraso da senescência foliar e o aumento da atividade da enzima redutase do nitrato (Venancio et al., 2003). Entretanto, esses resultados são extremamente variáveis, dependendo da cultura, da presença e da severidade da doença, assim como da época de aplicação do fungicida (Vincelli, 2012) apresentando, em alguns casos, efeitos negativos na produtividade (Da Costa et al., 2012).

O nitrogênio (N) é constituinte de aminoácidos, proteínas, inúmeras enzimas, nucleotídeos e clorofilas (Hayat et $a l ., 2010)$. Durante o crescimento e desenvolvimento vegetal, a disponibilidade de $\mathrm{N}$ pode ser fator limitante, influenciando a produção mais do que qualquer outro nutriente (Bredemeier \& Mundstock, 2000). No metabolismo desse nutriente pelo vegetal, devem ser considerados aspectos de absorção e de metabolização deste elemento (Bredemeier \& Mundstock, 2000), os quais podem ser afetados por fatores intrínsecos ou extrínsecos ao vegetal. Nesse sentido, o teor de clorofilas e de proteínas pode ser atribuído à maior assimilação de nitrogênio, que, por sua vez, requer a ação da enzima redutase do nitrato (RN). Ainda, a capacidade da planta para reduzir nitrato é controlada por uma série de fatores, como a disponibilidade de agentes redutores e do substrato no citosol (Sivasankar \& Oaks, 1995).

O tomateiro do cultivar Micro-Tom apresenta porte pequeno, crescimento rápido e ciclo médio de 70-90 dias, podendo ser cultivado em recipientes com reduzido volume de substrato (Martí et al., 2006). Graças à sua facilidade de transformação genética , o tomateiro "Micro-Tom" tem sido utilizado como um modelo biológico, em substituição a Arabidopsis thaliana.

Por essa razão, este trabalho teve como objetivo verificar o efeito de diferentes concentrações de nitrogênio, associadas à aplicação da piraclostrobina, em plantas de tomateiro 'Micro-Tom', sobre os teores de pigmentos fotossintéticos e de nitrogênio total e a atividade da redutase do nitrato.

\section{MATERIAL E MÉTODOS}

Sementes de tomateiro (Solanum lycopersicum L.) cv. Micro-Tom foram postas para germinar, em caixas tipo "gerbox", sobre duas folhas de papel mata-borrão umedecidas com água destilada, na proporção de 2,5 vezes a massa seca do papel, e transferidas para câmara de germinação tipo BOD, onde permaneceram por dez dias, em temperatura de $25 \pm 2{ }^{\circ} \mathrm{C}$ e luz constante (Brasil, 2009). Após esse período, as plântulas foram transplantadas para vasos de polietileno com volume de $500 \mathrm{~mL}$ de areia lavada em água, deixando-se uma planta por vaso.

As plantas foram cultivadas em casa de vegetação revestida com filme de polietileno de baixa densidade. A irrigação foi efetuada por meio do sistema de microaspersão, com tempo de irrigação de dois minutos e intervalo de seis horas. Após o transplante das mudas, foram realizadas três aplicações semanais da solução nutritiva de Hoagland \& Arnon (1950), segundo Passos (1996), sendo esta completa nos períodos iniciais.

Aos 21 dias após o transplante (DAT), as plantas foram submetidas aos tratamentos: T1 - solução nutritiva completa, sem aplicação de piraclostrobina; T2 - solução nutritiva completa, com aplicação piraclostrobina; T3 solução nutritiva com $1 / 2$ força iônica de nitrogênio, sem aplicação de piraclostrobina e T4, solução nutritiva com 1/2 força iônica de nitrogênio, com aplicação de piraclostrobina.

A aplicação do princípio ativo piraclostrobina foi realizada aos 21 e 35 DAT, por meio do produto Comet $^{\circledR}$, na

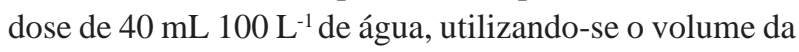
calda de $1000 \mathrm{~L} \mathrm{ha}^{-1}$ (25\% i.a - piraclostrobina), conforme recomendação do fabricante.

O delineamento experimental utilizado foi inteiramente casualizado, seguindo-se esquema fatorial 2 × 2 (duas doses de nitrogênio na solução nutritiva $\mathrm{x}$ presença ou ausência de piraclostrobina).

A determinação da atividade da redutase do nitrato (RN) e a quantificação dos pigmentos fotossintéticos e do nitrogênio total $\left(\mathrm{N}_{\text {total }}\right)$ foram realizadas aos 28 e 42 DAT, em um total de cinco repetições por tratamento, sendo cada unidade experimental representada por uma planta. A extração e a quantificação de clorofila $a, b$, total e de carotenoides nas folhas foram realizadas, segundo a metodologia proposta por Arnon (1949), e os resultados 
foram expressos em $\mu \mathrm{g} \mathrm{g}^{-1}$ massa fresca. Para o ensaio da atividade da redutase do nitrato em folhas, optou-se por seguir a metodologia proposta por Jaworski (1971), com modificações.

Para a quantificação de $\mathrm{N}_{\text {total }}$, o material vegetal seco, composto por folhas, caule e pecíolos, foi moído em moinho de facas tipo Willey e padronizado com peneira de 10 mesh, sendo posteriormente submetido à digestão sulfúrica. A concentração de $\mathrm{N}$-amoniacal foi determinada em ensaios, de acordo com Cataldo et al. (1975).

Os dados coletados foram submetidos à análise de variância pelo teste $\mathrm{F}$ e, as médias, comparadas pelo teste de Tukey, a 5\% de probabilidade de erro.

\section{RESULTADOS E DISCUSSÃO}

A análise de variância do conteúdo de pigmentos fotossintéticos, do nitrogênio total $\left(\mathrm{N}_{\text {total }}\right)$ e da redutase do nitrato $(\mathrm{RN})$ para plantas de tomateiro cv. Micro-Tom, submetidas a doses de nitrogênio e a uma aplicação de piraclostrobina, é apresentada na Tabela 1. Houve efeito significativo para a interação entre aplicação de piraclostrobina (presença e ausência) e doses de nitrogênio (solução nutritiva completa e solução nutritiva com $1 \frac{2}{2}$ força iônica de N), para as variáveis: clorofila $a$, clorofila $b$, clorofila total e carotenoides. Contudo, a interação não foi significativa para as variáveis $\mathrm{N}_{\text {total }}$ e RN (Tabela 1).

A aplicação de piraclostrobina reduziu a síntese dos pigmentos fotossintéticos das plantas cultivadas com solução nutritiva completa. Contudo, no cultivo, utilizando solução nutritiva com $1 \frac{1}{2}$ força iônica de $\mathrm{N}$, a aplicação de piraclostrobina não promoveu alteração dos teores de pigmentos fotossintéticos, entre as plantas que receberam o fungicida e as plantas que não foram pulverizadas.

Entre os pigmentos fotossintéticos, a clorofila $a$ e a clorofila total foram reduzidas nas plantas que receberam menor dose de N, em comparação com seus teores nas plantas cultivadas com solução nutritiva completa, ambas na ausência de piraclostrobina. A aplicação do fungicida foi capaz de promover o aumento da síntese de pigmentos das plantas submetidas a $1 / 2$ força iônica de N, em comparação com a das plantas cultivadas com a maior dose desse nutriente (Tabela 2).

Quanto à quantificação do $\mathrm{N}_{\text {total }}$ e da enzima $\mathrm{RN}$, pelo fato de não ter sido observada interação entre os fatores, procedeu-se à análise do efeito isolado de cada tratamento (Tabela 3). A maior concentração de $\mathrm{N}_{\text {total }}$ foi alocada em plantas submetidas a ambas as doses de N, sem a aplicação de piraclostrobina. Contudo, plantas cultivadas em solução nutritiva com $1 / 2$ força iônica de $\mathrm{N}$ apresentaram valores iguais aos dos tratamentos com piraclostrobina $\mathrm{e}$ a atividade da redutase do nitrato não diferiu entre os tratamentos testados.

Quando as plantas de tomate cv. Micro-Tom foram submetidas à segunda aplicação de piraclostrobina, o teste F da análise da variância não indicou interação entre as diferentes doses de nitrogênio e a presença ou ausência de piraclostrobina (Tabela 4).

Como não foi observada interação entre os fatores, procedeu-se à análise do efeito isolado de cada tratamento para os teores de pigmentos, para $\mathrm{N}_{\text {total }}$ e para atividade da enzima RN (Tabela 5 e 6 ). A ausência de piraclostrobina em plantas de tomate cv. Micro-Tom, cultivadas com diferentes doses de nitrogênio (T1 e T3), aumentou os valores de clorofila $a$, total e de carotenoides, em comparação com os dos demais tratamentos (Tabela 5).

Maiores valores de $\mathrm{N}_{\text {total }}$ foram encontrados em plantas de tomate submetidas a solução nutritiva com $1 / 2$ força iônica de N, sem aplicação de piraclostrobina $\left(29,37 \mathrm{mg} \mathrm{g}^{-}\right.$ ${ }^{1}$ massa seca) (Tabela 6). O tratamento com solução nutritiva completa, mais aplicação de piraclostrobina proporcionou menor teor de $\mathrm{N}_{\text {total }}$ (23,62 $\mathrm{mg} \mathrm{g}^{-1}$ massa seca), contudo, sem diferir de T4 e T1. Para a atividade da enzima RN, não foram observadas diferenças entre os tratamentos.

A atividade fungicida das estrobilurinas provém da sua capacidade para inibir a respiração mitocondrial por ligação ao citocromo $b$, localizado na membrana mitocondrial

Tabela 1: Resumo da análise de variância das variáveis analisadas em plantas de tomate cv. Micro-Tom, submetidas a doses de nitrogênio e a uma aplicação de piraclostrobina (28 DAT)

\begin{tabular}{lclllllc}
\hline \multirow{2}{*}{ Fatores de variação } & \multirow{2}{*}{$\mathbf{G}$} & \multicolumn{7}{c}{ Quadrado médio } \\
\cline { 3 - 8 } & & Cla & Clb & C T & Car & $\mathbf{N}_{\text {total }}$ & RN \\
\hline Nitrogênio (N) & 1 & $0,0016^{\text {ns }}$ & $0,0014^{\text {ns }}$ & $0,0062^{\text {ns }}$ & $0,0002^{\text {ns }}$ & $168,4321^{*}$ & $528,9164^{* *}$ \\
Piraclostrobina (P) & 1 & $0,0577^{*}$ & $0,0074^{*}$ & $0,1064^{* *}$ & $0,0071^{*}$ & $223,7270^{*}$ & $89,6211^{\text {ns }}$ \\
Int. NxP & 1 & $0,0476^{*}$ & $0,0030^{* *}$ & $0,0748^{* *}$ & $0,0025^{* *}$ & $5,2061^{\text {ns }}$ & $1,1563^{\text {ns }}$ \\
Tratamento & 3 & $0,0356^{*}$ & $0,0039^{*}$ & $0,0624^{*}$ & $0,0033^{*}$ & $132,4550^{*}$ & $206,5646^{\text {ns }}$ \\
Resíduo & 16 & 0,0027 & 0,0005 & 0,0026 & 0,0004 & 14,2071 & 66,4360 \\
\hline CV $(\%)$ & - & 4,9 & 6,5 & 3,7 & 6,9 & 10,9 & 11,3
\end{tabular}

GL - Graus de liberdade; Cla - clorofila $a$ ( $\mathrm{mg} \mathrm{g}^{-1}$ massa fresca); Clb - clorofila $b$ ( $\mathrm{mg} \mathrm{g}^{-1}$ massa fresca); CT - clorofila total (mg g-1 massa fresca); Car - Carotenoides ( $\mathrm{mg} \mathrm{g}^{-1}$ massa fresca); $\mathrm{N}_{\text {total }}$ - nitrogênio total ( $\mathrm{mg} \mathrm{g}^{-1}$ massa seca); $\mathrm{RN}$ - redutase do nitrato (nmol $\mathrm{g}^{-1}$ massa fresca $\mathrm{h}^{-1}$ ); Int. - Interação; CV - Coeficiente de variação. * *ignificativo a $1 \%$ de probabilidade $(\mathrm{p}<0,01)$. ** significativo a $5 \%$ de probabilidade $(\mathrm{p}<0,05)$. ${ }^{\text {ns }}$ Não significativo.

Rev. Ceres, Viçosa, v. 63, n.5, p. 676-682, set/out, 2016 
interna de fungos e de outros eucariotos, o que interrompe o ciclo de geração de energia, por impedir a produção de ATP (Bartlett et al., 2002). Segundo os mesmos autores, os vários fungicidas do grupo das estrobilurinas, disponíveis no mercado, apresentam diferentes propriedades físico-químicas, conferindo uma grande variedade de respostas referentes à planta, tanto relacionados à fisiologia quanto à sua morfologia.

As influências desses fungicidas no metabolismo vegetal vêm sendo denominadas de "efeito verde", por causa da associação com a capacidade das estrobilurinas de manter as folhas verdes por mais tempo. Neste trabalho, os resultados encontrados mostram que a aplicação da estrobilurina piraclostrobina em plantas de tomateiro cv. Micro-Tom não seguiu esta tendência.
A primeira aplicação de piraclostrobina reduziu a síntese de pigmentos nas plantas tratadas com o fungicida em comparação com as que não foram pulverizadas, ao serem comparadas apenas as plantas cultivadas com solução nutritiva completa. Esse comportamento também pode ser visualizado após a segunda aplicação, com a qual o fungicida foi capaz de reduzir os teores de pigmentos das plantas submetidas às duas condições de fornecimento de $\mathrm{N}$, evidenciando um efeito negativo sobre a variável em questão.

A redução da síntese de clorofila em função do efeito de estrobilurinas, também tem sido verificada por outros pesquisadores. Em trabalho realizado por Zhang et al. (2010), o fungicida à base de estrobilurina não foi capaz de impedir a diminuição do conteúdo de clorofilas em folhas-

Tabela 2: Teores de clorofila $a, b$ e total e pigmentos carotenoides, expressos em $\mathrm{mg} \mathrm{g}^{-1}$ massa fresca, em folhas de plantas de tomate cv. Micro-Tom, submetidas a doses de nitrogênio e a uma aplicação de piraclostrobina (28 DAT)

\begin{tabular}{|c|c|c|c|c|c|c|c|c|}
\hline \multirow{3}{*}{ Nitrogênio } & \multicolumn{8}{|c|}{ Aplicação de piraclostrobina } \\
\hline & \multicolumn{2}{|c|}{$\begin{array}{c}\text { Clorofila a } \\
\left(\mathrm{mg} \mathrm{g}^{-1} \text { massa fresca }\right)\end{array}$} & \multicolumn{2}{|c|}{$\begin{array}{c}\text { Clorofila b } \\
\text { (mg g-1 massa fresca) }\end{array}$} & \multicolumn{2}{|c|}{$\begin{array}{c}\text { Clorofila total } \\
\text { (mg g-1 massa fresca) }\end{array}$} & \multicolumn{2}{|c|}{$\begin{array}{c}\text { Carotenoides } \\
\text { (mg g-1 massa fresca) }\end{array}$} \\
\hline & $\mathbf{S} / \mathbf{P}$ & $\mathbf{C} / \mathbf{P}$ & $\mathbf{S} / \mathbf{P}$ & $\mathrm{C} / \mathrm{P}$ & $\mathbf{S} / \mathbf{P}$ & $\mathbf{C} / \mathbf{P}$ & $\mathbf{S} / \mathbf{P}$ & $\mathbf{C} / \mathbf{P}$ \\
\hline Solução completa & $1,163 \mathrm{aA}$ & $0,958 \mathrm{bB}$ & $0,355 \mathrm{aA}$ & $0,292 \mathrm{bB}$ & $1,519 \mathrm{aA}$ & $1,251 \mathrm{bB}$ & $0,320 \mathrm{aA}$ & $0,260 \mathrm{bB}$ \\
\hline $1 / 2$ forca de $N$ & $1,083 \mathrm{bA}$ & $1,074 \mathrm{aA}$ & $0,347 \mathrm{aA}$ & $0,334 \mathrm{aA}$ & $1,413 \mathrm{bA}$ & $1,408 \mathrm{aA}$ & $0,303 \mathrm{aA}$ & $0,288 \mathrm{aA}$ \\
\hline
\end{tabular}

S/P: tratamento sem aplicação de piraclostrobina; C/P: tratamento com aplicação de piraclostrobina. Médias seguidas de letras iguais, minúsculas nas colunas e maiúsculas nas linhas, não diferem entre si pelo teste de Tukey $(\mathrm{p}<0,05)$.

Tabela 3: Teor de nitrogênio total, expresso em $\mathrm{mg} \mathrm{g}^{-1}$ massa seca e atividade da redutase do nitrato, expressa em $\mathrm{nmol} \mathrm{g}^{-1}$ massa fresca $\mathrm{h}^{-1}$ em plantas de tomate cv. Micro-Tom, submetidas a doses de nitrogênio e a uma aplicação de piraclostrobina (28 DAT)

\begin{tabular}{|c|c|c|}
\hline Tratamentos & $\begin{array}{l}\text { Nitrogênio total } \\
\text { (mg g-1 massa seca) }\end{array}$ & $\begin{array}{c}\text { Redutase do nitrato } \\
\left(\mathrm{nmol} \mathbf{g}^{-1} \text { massa fresca } \mathbf{h}^{-1}\right)\end{array}$ \\
\hline $\mathrm{T} 1$ & $41,47 \mathrm{a}$ & $65,06 \mathrm{a}$ \\
\hline $\mathrm{T} 2$ & $33,76 \mathrm{~b}$ & $68,81 \mathrm{a}$ \\
\hline T3 & $34,64 \mathrm{ab}$ & $74,86 \mathrm{a}$ \\
\hline $\mathrm{T} 4$ & $28,98 \mathrm{~b}$ & $79,58 \mathrm{a}$ \\
\hline
\end{tabular}

Médias seguidas de letra iguais na coluna não diferem entre si pelo teste de Tukey $(\mathrm{p}<0,05)$. T1 - solução nutritiva completa sem aplicação de piraclostrobina; T2 - solução nutritiva completa + aplicação piraclostrobina; T3 - solução nutritiva 1/2 força iônica de nitrogênio sem aplicação de piraclostrobina e T4, solução nutritiva $1 \frac{1}{2}$ força iônica de nitrogênio + aplicação de piraclostrobina.

Tabela 4: Resumo da análise de variância das variáveis analisadas em plantas de tomate cv. Micro-Tom, submetidas a doses de nitrogênio e a duas aplicações de piraclostrobina (42 DAT)

\begin{tabular}{lclccccc}
\hline \multirow{2}{*}{ Fatores de variação } & \multirow{2}{*}{$\mathbf{G} \mathbf{L}$} & \multicolumn{7}{c}{ Quadrado médio } \\
\cline { 3 - 8 } & & Cla & Clb & $\mathbf{C T}$ & $\mathbf{C a r}$ & $\mathbf{N}_{\text {total }}$ & $\mathbf{R N}$ \\
\hline Nitrogênio (N) & 1 & $0,0009^{\text {ns }}$ & $0,0176^{*}$ & $0,0104^{\text {ns }}$ & $0,0008^{\text {ns }}$ & $52,9165^{* *}$ & $61,6145^{\text {ns }}$ \\
Piraclostrobina (P) & 1 & $0,7342^{*}$ & $0,0565^{*}$ & $1,1985^{*}$ & $0,0393^{*}$ & $31,1700^{\text {ns }}$ & $1522,9662^{*}$ \\
Int. NxP & 1 & $0,0122^{\text {ns }}$ & $0,0055^{\text {ns }}$ & $0,0341^{\text {ns }}$ & $0,0006^{\text {ns }}$ & $0,0130^{\text {ns }}$ & $160,3705^{\text {ns }}$ \\
Tratamento & 3 & $0,2491^{*}$ & $0,0265^{*}$ & $0,4143^{*}$ & $0,0136^{*}$ & $28,0332^{* *}$ & $581,6504^{* *}$ \\
Resíduo & 16 & 0,0046 & 0,0039 & 0,0099 & 0,0009 & 7,0709 & 176,6194 \\
\hline CV $(\%)$ & - & 8,0 & 21,7 & 8,8 & 14,1 & 10,0 & 20,5
\end{tabular}

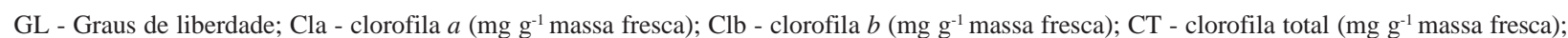
Car - Carotenoides ( $\mathrm{mg} \mathrm{g}^{-1}$ massa fresca); $\mathrm{N}_{\text {total }}$ - nitrogênio total ( $\mathrm{mg} \mathrm{g}^{-1}$ massa seca); $\mathrm{RN}$ - redutase do nitrato (nmol $\mathrm{g}^{-1} \mathrm{massa}$ fresca $\mathrm{h}^{-1}$ ); Int. - Interação; CV - Coeficiente de variação. *significativo a $1 \%$ de probabilidade $(\mathrm{p}<0,01)$. **significativo a $5 \%$ de probabilidade (p < $0,05) .{ }^{\text {ns }}$ Não significativo. 
bandeira de trigo. A aplicação de diferentes fungicidas com estribilurina como princípio ativo não alterou o conteúdo de clorofila de folhas de feijoeiro, quando comparado com o da testemunha absoluta; independentemente do tratamento, a resposta foi linear e decrescente, ao longo das épocas de avaliação (Kozlowski et al., 2009). Contudo, plantas de trigo, inoculadas com fungos saprófitos e tratadas com fungicidas do grupo químico das estrobirulinas, apresentaram retardo da senescência foliar (Bertelsen et al., 2001). Porém, os mesmos autores salientam que esse comportamento não correspondeu aos resultados encontrados em plantas não inoculadas com saprófitos, mostrando que o tratamento com fungicidas não influencia a senescência das plantas diretamente. Isso indica que o efeito positivo dos tratamentos com fungicidas foi causado pela inibição da atividade de promoção da senescência pelos fungos saprófitos e não por efeito direto sobre a fisiologia das plantas (Bertelsen et al., 2001).

Em relação ao conteúdo de nitrogênio total das plantas de tomate cv. Micro-Tom, a aplicação de estrobilurina piraclostrobina reduziu e, ou, não alterou essa variável, em relação à daquelas plantas que não receberam aplicação do fungicida. Sabe-se que os fungicidas podem afetar a concentração de nitrogênio, contudo essas respostas podem ser positivas (Herrman et al., 1996) ou negativas (Salmon \& Cook, 1987). Assim, Dimmock \& Gooding (2002) sugerem que as variações sobre a concentração de nitrogênio ocorrem, em parte, por causa do controle das diferentes doenças.
Para Kozlowski et al., (2009), os níveis normais de $\mathrm{N}_{\text {total }}$ das folhas para a cultura de feijoeiro, independentemente do tratamento, podem ser atribuídos, além da adubação, ao alto teor de matéria orgânica do solo na área experimental, disponibilizando uma maior quantidade de N, mascarando os efeitos fisiológicos das estrobilurinas. Esse fato pode ter influenciado os resultados deste trabalho, tendo em vista que, apesar do uso de substrato inerte (areia), o suplemento de nutrientes disponibilizado pela solução nutritiva de Hoagland \& Arnon encobriu, de certa forma, os resultados da aplicação de piraclostrobina.

Plantas superiores adquirem a maior parte do nitrogênio por meio da assimilação de nitrato. A enzima redutase do nitrato, que catalisa a transferência de elétrons a partir de $\mathrm{NAD}(\mathrm{P}) \mathrm{H}$ para a produção de nitrito, o qual é reduzido a $\mathrm{NH}_{4}^{+}$pela enzima redutase do nitrito, torna-se enzima-chave para a assimilação do nitrogênio e, consequentemente, importante variável a ser estudada. Neste trabalho, a aplicação de piraclostrobina não influenciou a atividade da redutase do nitrato nas duas concentrações de nitrogênio.

A redutase do nitrato é conhecida por ser uma enzima induzida pelo substrato. Em lâminas foliares de Brassica campestris L., Brassica chinensis var. oleifera e Spinacia oleracea $\mathrm{L}$, a atividade da enzima aumentou rapidamente com o acréscimo de $0,15 \mathrm{~g} \mathrm{~N} \mathrm{~kg}^{-1}$ de solo, mostrando que uma pequena quantidade de nitrato é suficiente para sua indução (Chen et al., 2004). Contudo, essa indução cessa quando a concentração de nitrato for maior que um determinado nível. O aumento da concentração de nitrato, para

Tabela 5: Teores de clorofila $a, b$ e total e pigmentos carotenoides, expressos em $\mathrm{mg} \mathrm{g}^{-1}$ massa fresca, em folhas de plantas de tomate cv. Micro-Tom, submetidas a doses de nitrogênio e a duas aplicação de piraclostrobina (42 DAT)

\begin{tabular}{|c|c|c|c|c|}
\hline Tratamentos & $\begin{array}{c}\text { Clorofila } a \\
\left(\mathrm{mg} \mathrm{g}^{-1} \text { massa fresca) }\right.\end{array}$ & $\begin{array}{c}\text { Clorofila } b \\
\left(\mathrm{mg} \mathrm{g}^{-1} \text { massa fresca) }\right.\end{array}$ & $\begin{array}{c}\text { Clorofila total } \\
\left(\mathrm{mg} \mathrm{g}^{-1} \text { massa fresca) }\right.\end{array}$ & $\begin{array}{c}\text { Carotenoides } \\
\left(\mathrm{mg} \mathrm{g}^{-1} \text { massa fresca) }\right.\end{array}$ \\
\hline $\mathrm{T} 1$ & $1,066 \mathrm{a}$ & $0,326 \mathrm{a}$ & $1,392 \mathrm{a}$ & $0,269 \mathrm{a}$ \\
\hline $\mathrm{T} 2$ & $0,633 \mathrm{~b}$ & $0,186 \mathrm{~b}$ & $0,819 \mathrm{~b}$ & $0,169 \mathrm{~b}$ \\
\hline $\mathrm{T} 3$ & $1,003 \mathrm{a}$ & $0,352 \mathrm{a}$ & $1,355 \mathrm{a}$ & $0,245 \mathrm{a}$ \\
\hline $\mathrm{T} 4$ & $0,669 \mathrm{~b}$ & $0,279 \mathrm{ab}$ & $0,948 \mathrm{~b}$ & $0,168 \mathrm{~b}$ \\
\hline
\end{tabular}

Médias seguidas de letra iguais na coluna não diferem entre si pelo teste de Tukey (p Â 0,05). T1 - solução nutritiva completa sem aplicação de piraclostrobina; T2 - solução nutritiva completa + aplicação piraclostrobina; T3 - solução nutritiva $1 \frac{1}{2}$ força iônica de nitrogênio sem aplicação de piraclostrobina e T4, solução nutritiva $1 / 2$ força iônica de nitrogênio + aplicação de piraclostrobina.

Tabela 6: Teor de nitrogênio total, expresso em $\mathrm{mg} \mathrm{g}^{-1}$ massa seca e atividade da redutase do nitrato, expressa em $\mathrm{nmol} \mathrm{g}^{-1} \mathrm{massa}$ fresca $\mathrm{h}^{-1}$, em plantas de tomate cv. Micro-Tom, submetidas a doses de nitrogênio e a duas aplicação de piraclostrobina (42 DAT)

\begin{tabular}{|c|c|c|}
\hline Tratamentos & $\begin{array}{c}\text { Nitrogênio total } \\
\text { (mg g-1 massa seca) }\end{array}$ & $\begin{array}{c}\text { Redutase do nitrato } \\
\left(\mathrm{nmol} \mathrm{g}^{-1} \text { massa fresca } \mathbf{h}^{-1}\right)\end{array}$ \\
\hline T1 & $26,06 \mathrm{ab}$ & $74,77 \mathrm{a}$ \\
\hline $\mathrm{T} 2$ & $23,62 \mathrm{~b}$ & $51,65 \mathrm{a}$ \\
\hline $\mathrm{T} 3$ & $29,37 \mathrm{a}$ & $72,62 \mathrm{a}$ \\
\hline $\mathrm{T} 4$ & $26,82 \mathrm{ab}$ & $60,83 \mathrm{a}$ \\
\hline
\end{tabular}

Médias seguidas de letras iguais na coluna não diferem entre si pelo teste de Tukey (p Â 0,05). T1 - solução nutritiva completa sem aplicação de piraclostrobina; T2 - solução nutritiva completa + aplicação piraclostrobina; T3 - solução nutritiva $1 \frac{1}{2}$ força iônica de nitrogênio sem aplicação de piraclostrobina e T4, solução nutritiva $1 \frac{1}{2}$ força iônica de nitrogênio + aplicação de piraclostrobina. 
$60 \mathrm{~g} \mathrm{~N} \mathrm{~kg}^{-1}$ de solo, fez que o RN presente em folhas de $S$. oleracea $\mathrm{L}$ atingisse um patamar elevado e, em folhas de B. campestris L. e B. chinensis var. oleífera, levasse à diminuição de sua atividade (Chen et al., 2004). Cabe salientar que a fonte de nitrogênio disponibilizada pela solução de Hoagland \& Arnon é exclusivamente na forma de nitrato, o que pode ter conferido aos resultados uma leve tendência ao decréscimo, quando em solução nutritiva completa.

Com base no mecanismo de ação das estrubilurinas, as plantas de bananeiras tratadas com azoxistrobina não apresentaram diferenças significativas entre os valores da área foliar, os teores de pigmentos fotossintéticos, os teores de $\mathrm{N}_{\text {total }}$, a atividade da $\mathrm{RN}$ e os aminoácidos livres totais, em comparação com os da plantas controle (Lima et al., 2012). Em plantas de feijoeiro, a aplicação de piraclostrobina promoveu aumento da taxa absoluta de crescimento, da área foliar e do rendimento de grãos sem, no entanto, apresentar influência sobre o índice de clorofila e o teor de $\mathrm{N}$ das folhas (Kozlowski et al., 2009). Esses resultados podem demonstrar que o efeito positivo no crescimento e na produtividade, ocasionado pelas estrobilurinas, pode estar relacionado com mecanismos adjacentes aos processos que envolvem a maximização do conteúdo de N nos tecidos vegetais (Kozlowski et al., 2009).

Com base nos resultados obtidos pode-se verificar que a aplicação de piraclostrobina em plantas de tomateiro cv. Micro-Tom não foi capaz de promover aumento da assimilação de $\mathrm{N}$, uma vez que não se observaram respostas positivas quanto à atividade da enzima RN e à alocação do nutriente nas plantas. Contudo, o papel do fungicida na promoção de crescimento nesse cultivar não deve ser descartado, tendo em vista que as estrobilurinas podem atuar nesse processo por meio de outros mecanismos, como, por exemplo, do aumento da fotossíntese líquida, em função da redução transitória da respiração mitocondrial, processo este que pode resultar em maior acúmulo de carboidratos.

\section{CONCLUSÃO}

Plantas de tomateiro cv. Micro-Tom, quando cultivadas com $1 / 2$ força iônica de nitrogênio e submetidas a uma aplicação de piraclostrobina, apresentam aumento dos teores de pigmentos fotossintéticos apenas aos 28 DAT.

Duas aplicações de piraclostrobina não influenciam no conteúdo de nitrogênio e na atividade da redutase do nitrato de plantas de tomateiro cv. Micro-Tom, cultivadas com solução nutritiva de Hoagland \& Arnon.

\section{AGRADECIMENTOS}

Os autores agradecem à Coordenação de Aperfeiçoamento de Pessoal de Nível Superior (CAPES), ao CNPq e à Fundação de Amparo à Pesquisa do Estado do Rio Grande do Sul (FAPERGS).

\section{REFERÊNCIAS}

Arnon DI (1949) Copper enzymes in isolates chloroplasts: polyphenoloxidase in Beta vulgaris. Plant physiology, 24:0115 .

Bartlett DW, Clough JM, Godwin JR, Hall AA, Hamer M \& ParrDobrzanski B (2002) The strobilurin fungicides. Pest Management Science, 58:649-662.

Bertelsen JR, Neergaard E \& Smedegaard-Petersen V (2001) Fungicidal effects of azoxystrobin and apoxiconazole on phyllosphere fungi, senescence and yield of winter wheat. Plant Pathology, 50:190-250.

Brasil (2009) Ministério da Agricultura e Reforma Agrária. Regras para Análise de Sementes. Brasília, SNAD/CLAV. 398p.

Bredemeier C \& Mundstock CM (2000) Regulação da absorção e assimilação do nitrogênio nas plantas. Ciência Rural, 30:365372.

Cataldo DA, Maroon M, Schrader LE \& Youngs VL (1975) Rapid colorimetric determination of nitrate in plant tissue by nitration of salicylic acid. Communications in Soil Science and Plant Analysis, 6:71-80.

Chen BM, Wang ZH, Li SX, Wang GX, Song HX \& Wang XN (2004) Effects of nitrate supply on plant growth, nitrate accumulation, metabolic nitrate concentration and nitrate reductase activity in three leafy vegetables. Plant Science, 167:635-643.

Da Costa RV, Cota LV, Da Silva DD, Meirelles WF \& Lanza FE (2012) Viabilidade técnica e econômica da aplicação de estrobilurinas em milho. Tropical Plant Pathology, 37:246-254.

Diaz-Espejo A, Victoria M, Ribas-Carbo M, Flexas J, Martorell S \& Fernández JE (2012) The effect of strobilurins on leaf gas exchange, water use efficiency and ABA content in grapevine under field conditions. Journal of Plant Physiology, 169:379-386.

Dimmock JPRE \& Gooding MJ (2002) The effects of fungicides on rate and duration of grain filling in winter wheat in relation to maintenance of flag leaf green area. Journal of Agricultural Science, 138:01-16.

Duarte RP, Juliatti FC \& Freitas PT (2009) Eficácia de diferentes fungicidas na cultura do milho. Bioscience Journal, 25:101-111.

Hayat R, Ali S, Amara U, Khalid R \& Ahmed I (2010) Soil beneficial bacteria and their role in plant growth promotion: a review. Annals Microbiology, 60:579-598.

Henry RS, Johnson WG \& Wise KA (2011) The impact of a fungicide and an insecticide on soybean growth, yield, and profitability. Crop Protection, 30:1629-1634.

Herrman TJ, Bowden RL, Loughin T \& Bequette RK (1996) Quality Response to the Control of Leaf Rust in Karl Hard Red Winter Wheat. Cereal Chemistry, 73:235-238.

Hoagland DR \& DI Arnon (1950) The water-culture method for growing plants without soil. California Agricultural Experiment Station Circular, 347:01-32.

Jaworski EG (1971) Nitrate reductase assay in intact plant tissues. Biochemical and Biophysical Research Communications, 43:1274-1279.

Kozlowski LA, Simões DFM, Souza CD \& Trento M (2009) Efeito fisiológico de estrobilurina $\mathrm{F} 500^{\circledR}$ no crescimento e rendimento do feijoeiro. Revista Acadêmica: Ciências Agrárias e Ambientais, 7:41-54.

Lima A dos S, Reffatti TN, Junco SMC, Burbulhan T \& Martikoski L (2009) Physilogical effect of the fungicide Pyraclostrobin and seed treatment in the corn crop. Applied Research \& Agrotechnology, 2:113-128. 
Lima JD, Moraes W da S \& Silva SHM-G da (2012) Respostas fisiológicas em mudas de bananeira tratadas com estrobilurinas Semina: Ciências Agrárias, 33:77-86.

Martí E, Gisbert C, Bishop GJ \& Dixon MS (2006) Genetic and physiological characterization of tomato cv. Micro-Tom. Journal of Experimental Botany, 57:2037-2047.

Passos LP (1996) Métodos analíticos e laboratoriais em fisiologia vegetal. Coronel Pacheco, Embrapa/CNPGL. 223p.

Salmon SE \& Cook RJ (1987) Effects of fungicides on the milling and baking quality of wheat. Aspects of Applied Biology, 15:373384 .

Santana FM, Clebsch CC, Lazzarotto A \& Garcez JG (2011) Avaliação da eficiência de controle da mancha amarela em duas cultivares de trigo da Embrapa Trigo, safra 2010. Passo Fundo, Embrapa Trigo. 19p. (Documentos online, 129).

Sivasankar S \& Oaks A (1995) Regulation of nitrate reductase during early seedling growth. Plant Physiology, 107:1225-1231.

Sudisha J, Amruthesh KN, Deepak SA, Shetty NP, Sarosh BR \& Shetty SH (2005) Comparative efficacy of strobilurin fungicides against downy mildew disease of pearl millet. Pesticide Biochemistry and Physiology, 81:188-197.
Tsumanuma GM, Carvalho SJP de, Fancelli AL, Bernardes MS, Rodrigues MAT \& Begliomini E (2010) Crescimento de dois cultivares de soja submetidos a aplicações de herbicidas e fungicidas. Revista Ceres, 57:742-750.

Venancio WS, Rodrigues MAT, Begliomini E \& Souza NLD (2003) Physiological effects of strobilurin fungicides on plants. Publicatio UEPG: Ciências Exatas e da Terra, Ciências Agrárias e Engenharias, 9:59-68.

Vincelli P (2012) QoI (strobilurin) fungicides: benefits and risks. Plant Health Instructor. Disponível em <http://dx.doi.org/ 10.1094/PHI-I-2002-0809-02>. Acessado em: 23 de abril de 2014.

Zhang YJ, Zhang X, Zhou MG, Chen CJ, Wang JX, Wang HC \& Zhang H (2010) Effect of fungicides JS399-19, azoxystrobin, tebuconazole, and carbendazim on the physiological and biochemical indices and grain yield of winter wheat. Pesticide Biochemistry and Physiology, 98:151-157. 